\title{
VARIABILIDADE ISOENZIMÁTICA EM OITO RAÇAS DE MILHO ${ }^{(1)}$
}

\author{
SÉRGIO EMÍLIO DOS SANTOS VALENTE ${ }^{(2,3)}$, MARCOS APARECIDO GIMENES ${ }^{(3)}$ \\ \& CATALINA ROMERO LOPES ${ }^{(3)}$
}

\begin{abstract}
RESUMO
Com o objetivo de avaliar a variabilidade genética e as relações de afinidade entre dezenove populações de oito raças de milho (Zea mays L.) - as comerciais antigas Cateto Sulino, Cateto Sulino Grosso, Cateto Nortista e Canario de Ocho, e as raças indígenas Moroti, Lenha, Entrelaçado e Caingang - analisaram-se os seguintes sistemas enzimáticos: glutamato oxalacetato transaminase (GOT), esterase (EST) e malato desidrogenase (MDH). Observou-se maior semelhança entre as raças pertencentes a um mesmo grupo, mas as populações analisadas não se agruparam de acordo com as raças, classificadas anteriormente segundo caracteres morfológicos. Os sistemas enzimáticos utilizados não permitiram a caracterização individual de cada uma das raças analisadas. As indígenas apresentaram maior variabilidade do que as comerciais antigas quanto ao número de alelos por loco e à porcentagem de locos polimórficos.
\end{abstract}

Termos de indexação: Zea mays L., variabilidade genética, eletroforese de isoenzimas.

\footnotetext{
(1) Recebido para publicação em 6 de novembro de 1997 e aceito em 25 de março de 1999.

(2) Faculdade de Ciências da Saúde da Universidade de Marília (UNIMAR), Câmpus Universitário, 17525-902 Marília (SP).

(3) Departamento de Genética da Universidade Estadual Paulista (UNESP), Distrito de Rubião Júnior s/n, 18618-000 Botucatu (SP).
} 


\title{
ABSTRACT \\ ISOENZYME VARIATION AMONG EIGHT RACES OF MAIZE
}

\begin{abstract}
The objective of this study was to evaluate the genetic variability and affinity relationships among eight races of maize (Zea mays L.): four ancient varieties (Cateto Sulino, Cateto Sulino Grosso, Cateto Nortista and Canario de Ocho) and four indigenous (Moroti, Lenha, Entrelaçado and Caingang), through isoenzymatic polymorphisms. The following isoenzymatic systems were evaluated: Glutamate Oxaloacetate Transaminase (GOT), Esterase (EST) and Malate Dehydrogenase (MDH). It was observed a higher identity among races belonging to the same racial group; however, populations within each race were not grouped according, to previous morphological classification. Indigenous races showed higher average number of alleles per loci and percentage of polymorphic loci than the ancient varieties. This fact might be due to the selection the ancient varieties had been gone through.
\end{abstract}

Index terms: Zea mays L., genetic variability, isoenzyme electrophoresis.

\section{INTRODUÇÃO}

Segundo Paterniani \& Goodman (1978), realizaram-se esforços para coletar e preservar as variedades de milho das Américas, pois a preservação da diversidade contida nesse material é de grande importância para o futuro da pesquisa e melhoramento da espécie.

No território brasileiro, encontraram-se vários grupos raciais de milho, destacando-se dois: as variedades comerciais antigas (Cateto Sulino, Cateto Sulino Grosso, Cateto Nortista e Canario de Ocho) e as raças indígenas (Moroti, Lenha, Entrelaçado e Caingang). Apesar de não apresentarem valor comercial, tais raças podem ser utilizadas em programas de melhoramento por suas várias características agronômicas de interesse: alto número de fileiras de grãos, baixa inserção da espiga e grãos com múltiplas camadas de aleurona, resultando em um aumento da quantidade e da qualidade de proteína contida no grão (Paterniani \& Goodman, 1978).

O grupo de raças indígenas foi definido pelas tribos de índios que as cultivaram pelas suas características, como endosperma mole, aleurona amarela e espigas grossas. Já as comerciais antigas foram agru- padas por serem cultivadas em maior escala (Paterniani \& Goodman, 1978).

A análise da variabilidade nas raças indígenas e comerciais antigas é de grande importância, uma vez que híbridos comerciais as têm substituído por serem mais produtivos. Além disso, a descaracterização da cultura indígena levou à perda de muitas de suas tradições, entre as quais o cultivo de determinados tipos de milho. Grande parte dessas amostras, portanto, não poderá mais ser recoletada, restando apenas o material existente nos Bancos Ativos de Germoplasma (BAGs).

Marcadores moleculares e bioquímicos têm-se mostrado de grande utilidade para a análise da variabilidade e relações genéticas em espécies vegetais ( $\mathrm{Lu}$ \& Pickersgill, 1993; Maass et al., 1993; Phillips et al., 1993; Galgaro \& Lopes, 1994; Stalker et al., 1994; Maquet et al., 1997; Sawazaki et al., 1997). As isoenzimas se destacam por serem marcadores de baixo custo e relativamente simples. Além disso, permitem estimar a distribuição da diversidade genética entre populações e espécies (Dubreuil \& Charcosset, 1998).

Em vista de que ainda pouco se conhece a respeito da variabilidade de nossas raças indígenas e co- 
merciais antigas de milho, o objetivo do presente trabalho é avaliar a variabilidade genética e estudar as relações filogenéticas existentes dentro das e entre as raças indígenas e as variedades comerciais antigas de milho, mediante a análise eletroforética de isoenzimas.

\section{MATERIAL E MÉTODOS}

O material biológico, cedido pelo Dr. Ernesto Paterniani, ESALQ-USP/ Piracicaba (SP), é constituído por amostras de dezenove populações de oito raças de milho, mantidas no banco de germoplasma do Centro de Sementes da AGROCERES, localizado em Santa Cruz das Palmeiras (SP). As populações foram estabelecidas usando-se caracteres morfológicos, dadas as seguintes razões: indisponibilidade de espaço para estocagem e mão-de-obra insuficiente para manutenção das coleções individuais (Paterniani \& Goodman, 1978).
As análises eletroforéticas foram realizadas a partir de extratos de coleóptilos com $15 \mathrm{~mm}$ de comprimento, retirados de sementes após germinação de dois dias no escuro à temperatura ambiente. Foram analisados 260 indivíduos das seguintes raças: Cateto Sulino, Cateto Sulino Grosso, Cateto Nortista, Canario de Ocho, Moroti, Lenha, Entrelaçado e Caingang (Quadro 1).

Como camada suporte para eletroforese foi utilizada penetrose a $13 \%$. As técnicas de extração, de separação eletroforética e de coloração dos sistemas enzimáticos adotadas foram as descritas por Stuber et al. (1988) e Kephart (1990). Foram analisados os seguintes sistemas enzimáticos: glutamato oxalacetato transaminase (GOT), esterase (EST) e malato desidrogenase (MDH).

Os genótipos de cada indivíduo e as freqüências alélicas foram inferidos a partir dos padrões eletroforéticos. As freqüências alélicas determinadas em cada população e raça nos seis locos analisados

Quadro 1. Relação das raças indígenas e comerciais antigas de milho (Zea mays L.), submetidas à análise eletroforética de isoenzimas
Raças
Populações ${ }^{(1)}$

\section{Comerciais antigas}
1. Cateto Sulino (CS)
UR II, ARG III, UR V
2. Cateto Sulino Grosso (CSG) ..
UR III
3. Cateto Nortista $(\mathrm{CN})$
SUR I
4. Canario de Ocho $(\mathrm{CO})$
ARG IV, ARG VI

\section{Indígenas}

5. Moroti (M)

6. Caingang $(\mathrm{C})$

7. Lenha (L)

8. Entrelaçado (E)
PR II, PE I, MT III, PAG VI, PAG VII, BOL I, PAG VIA

PR III, SP XIV, CC

RS XX

MT VI

(1) $\mathrm{ARG}=$ Argentina, $\mathrm{BOL}=$ Bolívia, $\mathrm{CC}=$ Caingang Composto, $\mathrm{MT}=$ Mato Grosso, $\mathrm{PAG}=$ Paraguai, $\mathrm{PE}=\mathrm{Pernambuco}, \mathrm{PR}=\mathrm{Paraná}$, RS $=$ Rio Grande do Sul, SP = São Paulo, SUR = Suriname e UR = Uruguai. 
foram convertidas em similaridade genética, usando-se o método de Rogers do programa BIOSYS versão 1.7 (Swofford \& Selander, 1989). Para a construção dos fenogramas, empregou-se o método do UPGMA (Unweigthed pair group method with arithmetic average - Média aritmética não ponderada para agrupamento aos pares), segundo Michener \& Sokal (1957).

\section{RESULTADOS E DISCUSSÃO}

A Figura 1 mostra um gel e um esquema dos genótipos observados na esterase (EST). Foram encontradas nesse sistema duas zonas anódicas de atividade passíveis de análise (1 e 2), as quais possibilitaram a determinação dos genótipos. Tais zonas se referem, respectivamente, aos locos 8 e 9, discutidos por Stuber et al. (1988). Na zona 1 (EST 8) encontrou-se apenas uma banda, indicando ser este um loco monomórfico na amostra analisada. Já na 2 (EST 9), observaram-se 3 padrões de banda, 2 deles formados por uma banda e o terceiro por duas bandas de mobilidade igual à encontrada nos dois outros padrões. Os padrões de bandas sugerem que as enzimas codificadas no loco EST 9 referem-se a enzimas monoméricas (formadas por uma cadeia polipeptídica), em vista de não terem sido observadas bandas extras resultantes da junção de polipeptídeos codificados pelos dois alelos no heterozigoto.

No sistema da glutamato oxalacetato transaminase (GOT), encontraram-se três zonas de atividade anódicas (Figura 2). As duas de maior mobilidade referem-se, respectivamente, aos locos GOT 2 e GOT 3. Nestes, verificou-se apenas uma banda em todas as amostras analisadas, sendo, portanto, ambos monomórficos. A zona de menor mobilidade apresentou 3 padrões, sendo 2 formados apenas por uma banda (homozigotos) e 1, por 3 bandas (heterozigotos), referindo-se ao loco GOT 1. As três zonas analisadas estudadas e discutidas previamente por Stuber et al. (1988) - referem-se a uma enzima dimérica, isto é, formada pela junção de duas cadeias polipeptídicas.
$\mathrm{Na}$ malato mesidrogenase (MDH), observou-se um padrão complexo de bandas, todas anódicas e de mobilidade semelhante. Foi utilizado apenas o loco dimérico MDH 2, descrito também por Stuber et al. (1988), pela impossibilidade de uma análise segura dos demais locos, uma vez que suas isoenzimas ou comigram ou possuem uma mobilidade muito semelhante ou, ainda, combinam-se formando heterodímeros interlocos. Na região do gel onde migraram as isoenzimas codificadas no MDH 2, pode-se observar, no mínimo, uma e, no máximo, quatro bandas. As bandas extras são produtos de outros locos ou heterodímeros interlocos. A Figura 3 mostra um gel apenas com a região analisada e um esquema dos genótipos observados na MDH.

O número de indivíduos analisados e de alelos por loco e a porcentagem de locos polimórficos, em cada população analisada, encontram-se no Quadro 2: foi encontrada uma média de 1,5 alelo por loco, variando de 1,7 para as populações SP XIV, PR III, CC, PAG VII e PR II a 1,3 para PAG VI, PAG VI-A, SUR I, UR III e ARG VI. A porcentagem de locos polimórficos variou de $16,7 \%$ para a ARG VI, a 50,0\% para as populações MT VI, RS XX, SP XIV, PR III, CC, PAG VII, PR II, MT III, ARG III, ARG IV e UR V.

As raças indígenas apresentaram, em média, maior número de alelos por loco $(1,5)$ e maior porcentagem de locos polimórficos $(44,4 \%)$ do que as comerciais antigas $(1,4$ alelo/loco e $40,5 \%$ de locos polimórficos).

Detectou-se, portanto, maior variabilidade na amostra analisada das raças indígenas do que na das comerciais antigas (Quadro 2). Estas últimas, apesar de serem originariamente domesticadas pelos indígenas, sofreram grandes alterações devidas ao cultivo pelo homem branco (Paterniani \& Goodman, 1978). Tais alterações levaram, provavelmente, a maior uniformidade e à diminuição da variabilidade genética.

Stuber \& Moll (1972) verificaram que, em milho, a seleção para aumento de rendimento em uma população, gerada a partir de um cruzamento simples, levava ao aumento da freqüência de um alelo de fosfatase ácida. 


\section{GENÓTIPOS}

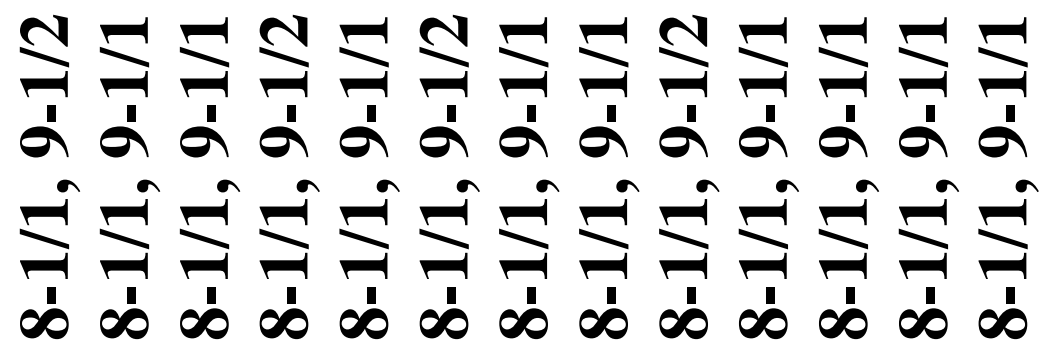

Est 8

Est 9

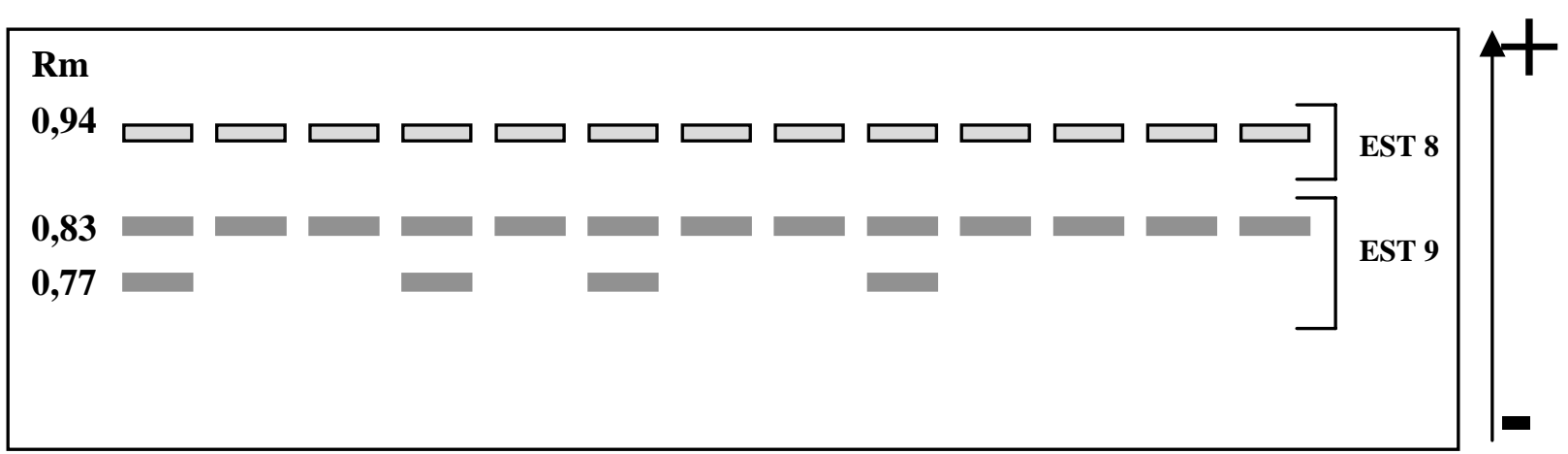

Figura 1. Zimograma de esterase (EST) de milho mostrando os genótipos (loco 8, monomórfico, e loco 9, polimórfico, com alelos 1 e 2) e fenótipos encontrados nas populações das raças analisadas. 


\section{GENÓTIPOS}

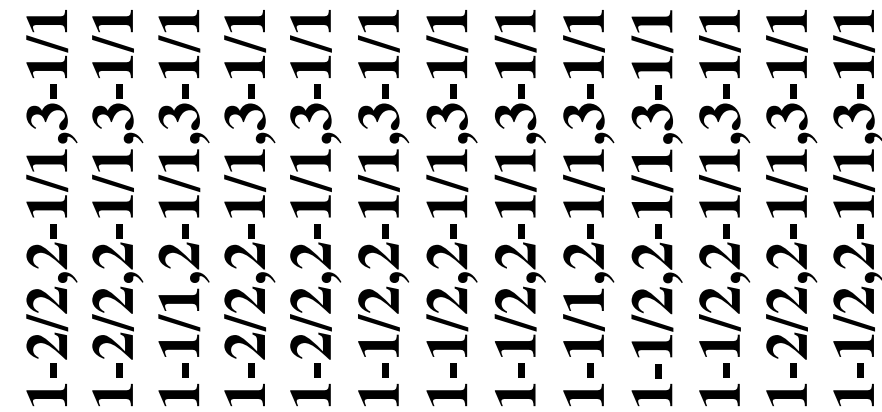

\section{GOT 3}

GOT 2

GOT 1
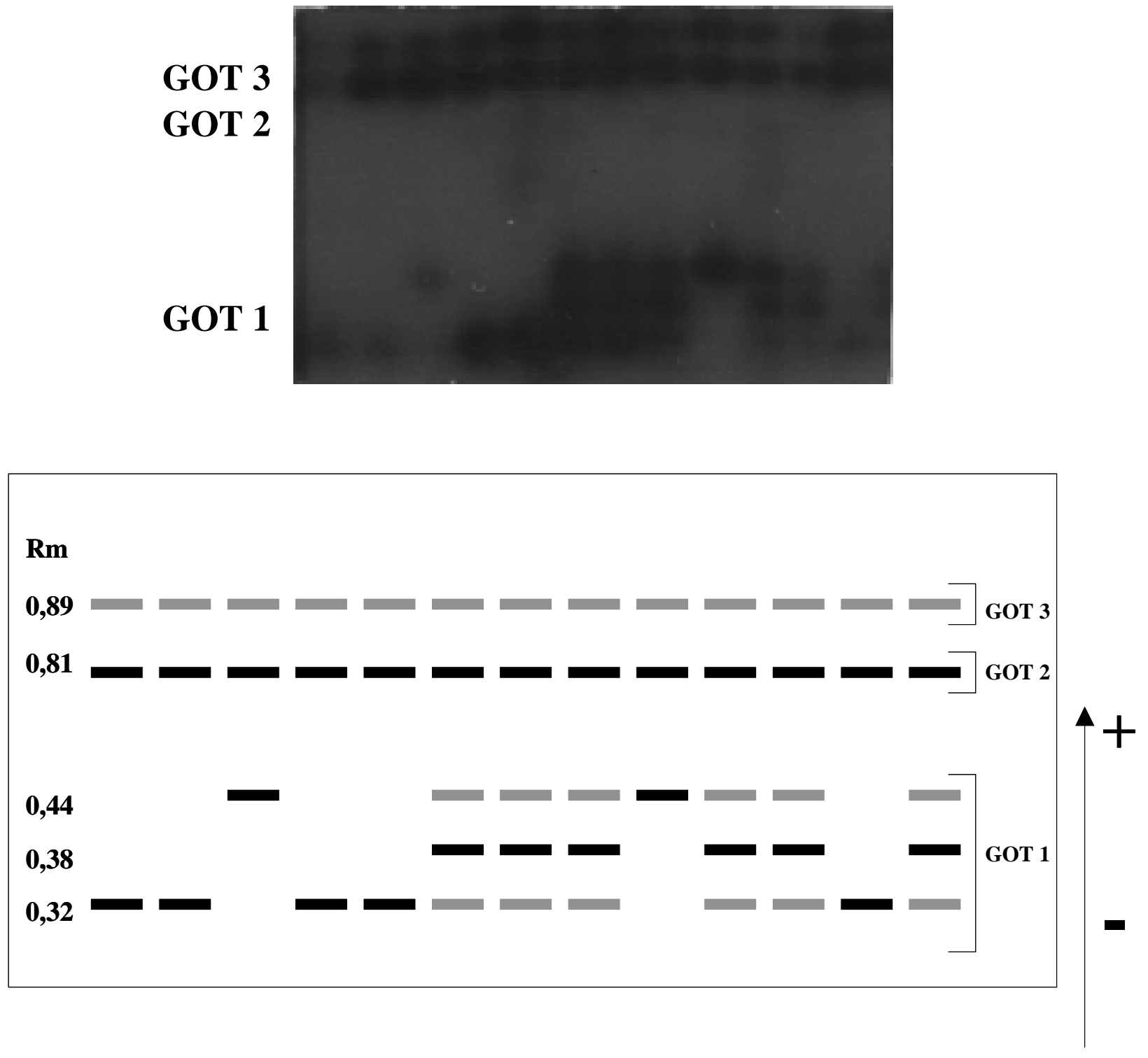

Figura 2. Zimograma de glutamato oxalacetato transaminase (GOT) de milho mostrando os genótipos (loco 1, polimórfico, com alelos 1 e 2; locos 2 e 3, monomórficos) e fenótipos encontrados nas populações das raças analisadas. 


\section{GENÓTIPOS}

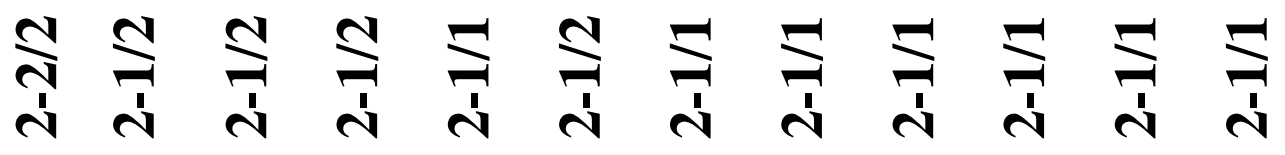

\section{MDH2}

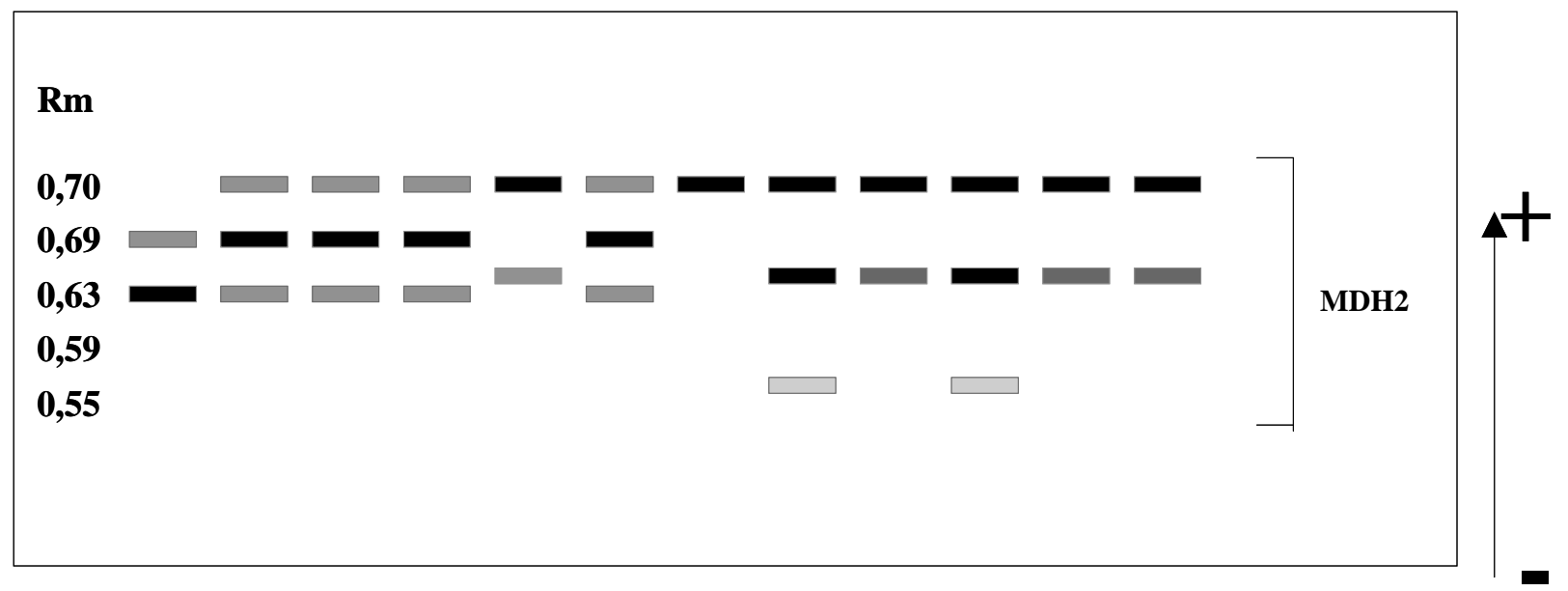

Figura 3. Zimograma de malato desidrogenase (MDH) de milho mostrando os genótipos (loco 2, polimórfico, com alelos 1 e 2) e fenótipos encontrados nas populações das raças analisadas. 
Os fenogramas resultantes do agrupamento UPGMA, com base na distância genética de Rogers (1972) constam das Figuras 4 e 5. Não se observou concordância entre dados morfológicos e isoenzimáticos ao nível de raças, isto é, as populações não se agruparam de acordo com as raças às quais pertencem. Por outro lado, as raças agruparam-se conforme com o seu grupo racial, e que foi estabele- cido de acordo com caracteres morfológicos segundo Paterniani \& Goodman (1978) (Figuras 4 e 5).

Dentro de cada um dos dois grandes grupos - Figura 4 - populações de raças diferentes foram mais similares entre si do que aquelas de uma mesma raça, como, por exemplo, as populações Ur III e Sur I, que, apesar de pertencerem a raças diferentes, apresentaram pequena distância genética.

Quadro 2. Variabilidade genética nos seis locos em dezenove populações das oito raças estudadas de milho

\begin{tabular}{ccccc}
\hline Raças & Populações $^{(1)}$ & $\begin{array}{c}\text { Tamanho da } \\
\text { amostra }\end{array}$ & $\begin{array}{c}\text { Alelos por } \\
\text { loco }\end{array}$ & $\begin{array}{c}\text { Locos } \\
\text { polimórficos }\end{array}$ \\
\hline
\end{tabular}

\section{Indígenas}

Entrelaçado

Lenha...

Caingang

Moroti

\section{Comerciais Antigas}

Cateto Nortista

SUR I

20

UR III

20

Cateto Sulino Grosso ..

Cateto Sulino

UR II

20

UR V

20

ARG III

ARG VI

10

10

10

10

10

10

10

10

10

10

10

10
Canario de Ocho

20

20

20
1,5

50,0

1,5

50,0

1,7

50,0

1,7

50,0

1,7

50,0

1,3

33,3

1,3

33,3

1,7

50,0

1,5

33,3

1,5

33,3

1,7

50,0

1,5

50,0

1,3

33,3

1,3

33,3

1,5

50,0

1,5

50,0

1,5

50,0

1,3

16,7

(1) Ver nota do Quadro 1. 


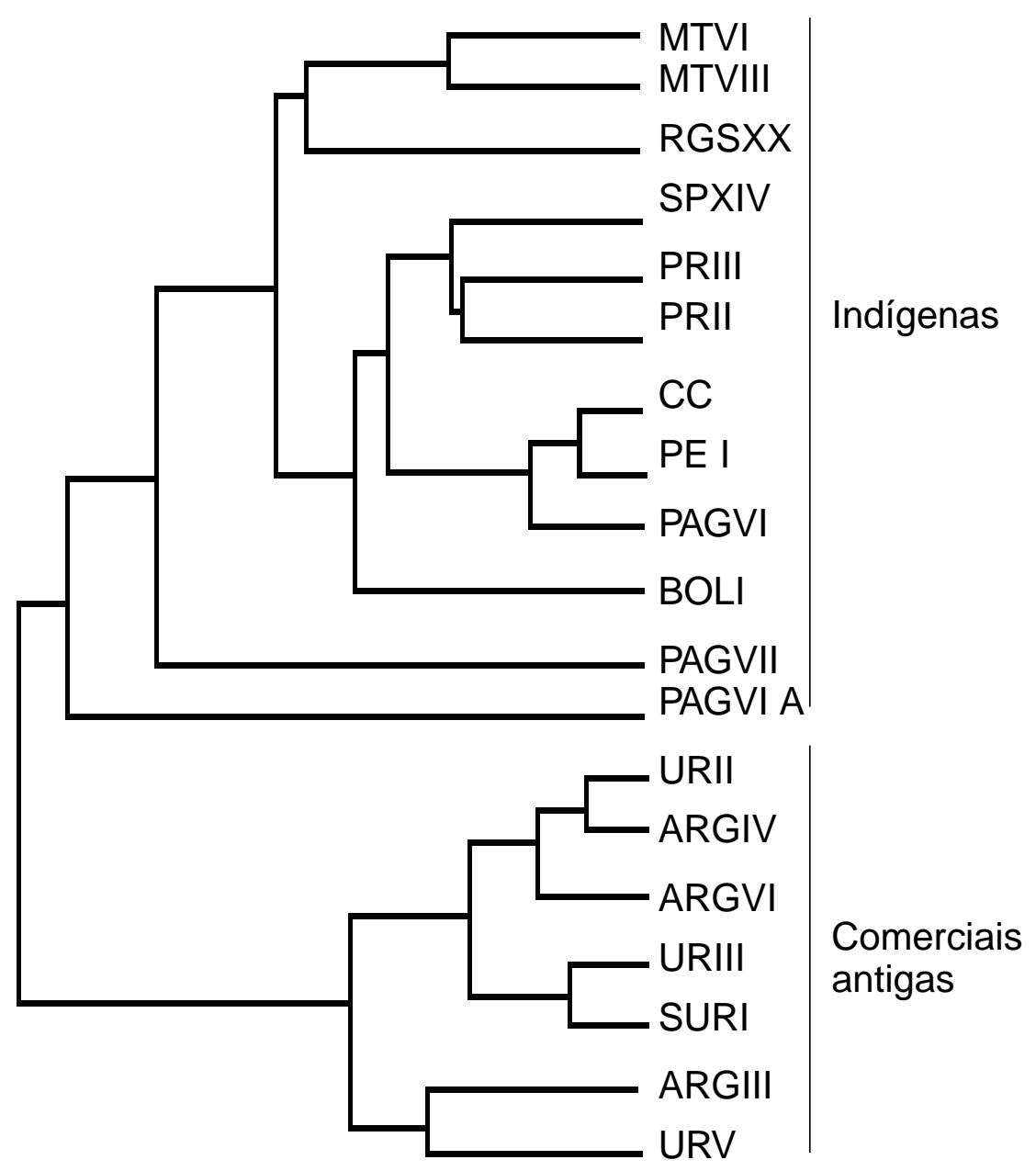

$0,33 \quad 0,27 \quad 0,20 \quad 0,13 \quad 0,07 \quad 0,00$

Figura 4. Fenograma calculado a partir das frequiências genotípicas dos seis locos detectados: dois de esterase (EST); três de aspartato amino transferase (AAT) e um de malato desidrogenase (MDH), nas dezenove populações distribuídas pelas oito raças de milho. 

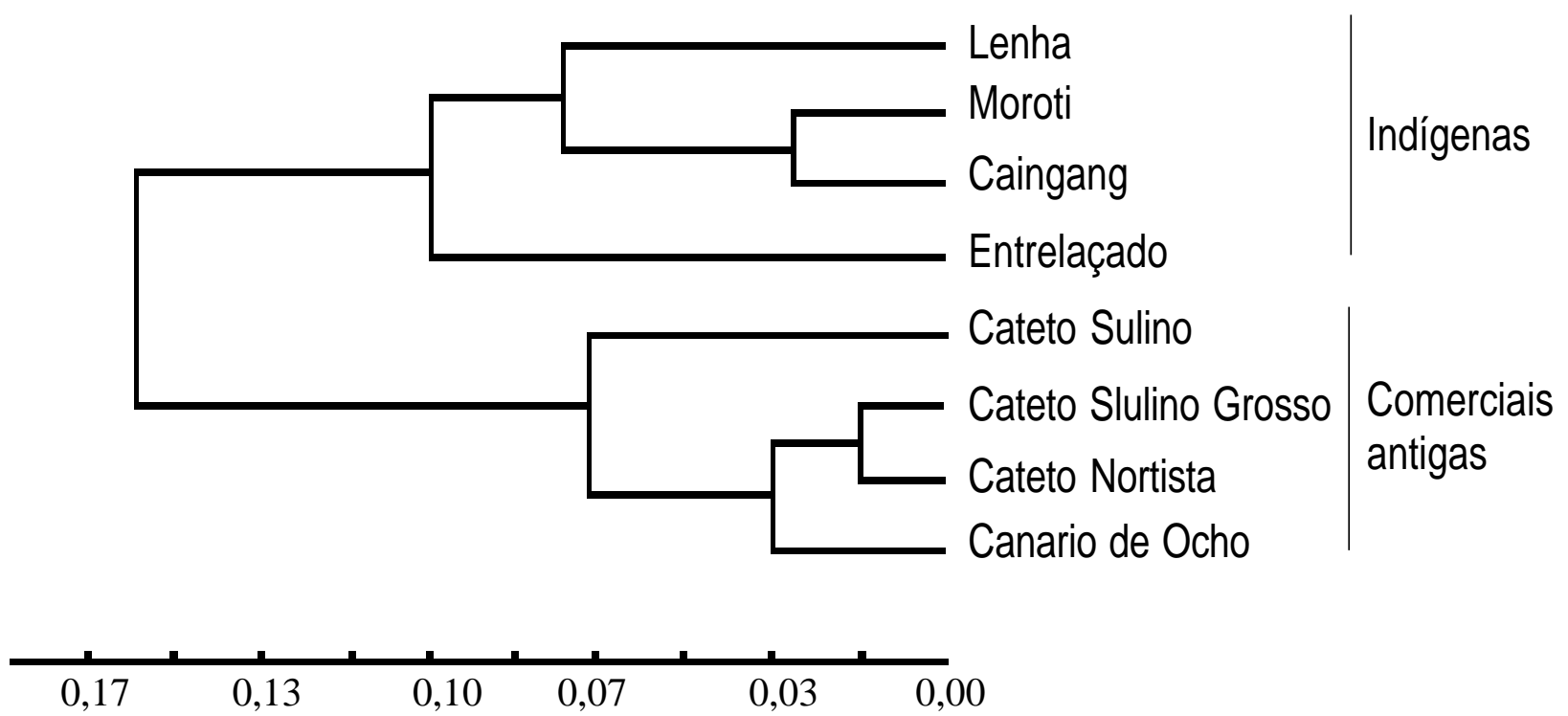

Figura 5. Fenograma calculado a partir das freqüências genotípicas dos seis locos detectados (Wright, 1978): dois de esterase (EST); três de aspartato amino transferase (AAT) e um de malato desidrogenase (MDH), nas dezenove populações distribuídas pelas oito raças de milho.

Segundo Gottlieb (1981), a discordância entre dados morfológicos e isoenzimáticos não é surpreendente, pois os caracteres morfológicos são escolhidos em vista de sua constância taxonômica e não por indicarem forte diferenciação genética. Lewandowski \& Mejnartowicz (1991) apontaram como causa para discordância o fato de que forças evolutivas estão agindo diferentemente nesses dois grupos de caracteres ou, ainda, que os genes aloenzimáticos podem não ter significado evolutivo.

\section{CONCLUSÕES}

1. As raças indígenas apresentaram maior número de alelos por loco e maior porcentagem de locos polimórficos do que as comerciais antigas.

2. As populações das raças analisadas não se agruparam de acordo com as raças às quais pertencem, pelos resultados isoenzimáticos. Por outro lado, as raças agruparam-se conforme o seu grupo racial, e que foi estabelecido segundo os caracteres morfológicos.

\section{AGRADECIMENTOS}

Ao Dr. Ernesto Paterniani, da ESALQ-USP/ - Piracicaba (SP), e à AGROCERES - Santa Cruz das Palmeiras (SP), pelo fornecimento do material para análise.

\section{REFERÊNCIAS BIBLIOGRÁFICAS}

DUBREUIL, P. \& CHARCOSSET, A. Genetic diversity within and among maize populations: a comparison between isozyme and nuclear RFLP loci. Theoretical and Applied Genetics, Berlin, 96:577-587, 1998. 
GALGARO, M.L. \& LOPES, C.R. Isoenzymatic variability among five peanut cultivars. Bragantia, Campinas, 53(2): 135-140, 1994.

GOTTLIEB, L.D. Electrophoretic evidence and plant systematics. Progress in Phytochemistry, Elmslord, 7: 1-46, 1981.

KEPHART, S.R. Starch gel electrophoresis of plant isozymes: a comparative analysis of techniques. American Journal of Botany, Columbus, 77:693-712, 1990.

LEWANDOWSKI, A. \& MEJNARTOWICZ, L. Levels and patterns of allozyme variation in some european larch (Larix decidua) populations. Hereditas, Landskrona, 115:221-226, 1991.

LU, J. \& PICKERSGILL, B. Isozyme variation and species relationships in peanut and its wild relatives (Arachis L. Leguminosae). Theoretical and Applied Genetics, Berlin, 85:550- 560, 1993.

MAASS, B.L.; TORRES, A.M. \& OCAMPO, C.H. Morphological and isozyme characterisation of Arachis pintoi Krap. \& Greg. nom. nud. germplasm. Euphytica, Dordrecht, 70:43-52, 1993.

MAQUET, A.; BI ZORO, I.; DELVAUX, M.; WATHELET, B. \& BAUDOIN, J.P. Genetic structure of a Lima bean base collection using allozyme markers. Theoretical and Applied Genetics, Berlin, 95:980-991, 1997.

MICHENER, C.D. \& SOKAL, R.R. A quantitative approach to a problem in classification. Evolution, Lawrence, 11: 130-162, 1957.
PATERNIANI, E. \& GOODMAN, M.M. Races of maize in Brazil and adjacent areas. México, International Maize and Wheat Improvement Center, 1978. 95p.

PHILLIPS, T.D.; MURPHY, J.P. \& GOODMAN, M.M. Isozyme variation in germplasm accessions of the wild oat Avena sterilis L. Theoretical and Applied Genetics, Berlin, 86:54-64, 1993.

SAWAZAKI, H.E.; NAGAI, H. \& SODEK, L. Caracterização da variabilidade genética em couve-manteiga utilizando isoenzimas e RAPD. Bragantia, Campinas, 56(1):9 -19, 1997.

STALKER, H.T.; PHILLIPS, T.D. \& MURPHY, J.P. Variation of isozyme patterns among Arachis species. Theoretical and Applied Genetics, Berlin, 87:746-755, 1994.

STUBER, C. \& MOLL, R.H. Frequency changes of isozyme alleles in a selection experiment for grain yield in maize (Zea mays L.). Crop Science, Madison, 12:337-340, 1972.

STUBER, C.W.; WENDEL, J.F.; GOODMAN, M.M. \& SMITH, J.S.C. Techniques and scoring procedures of starch gel electrophoresis of enzymes from maize (Zea mays L.). Raleigh, North Caroline State University., 1988. p.1-87. (Technical Bulletin, 286)

SWOFFORD, D.L. \& SELANDER, R.B. BIOSYS - 1. A computer program for the analysis of allelic variation in population genetics and biochemical systematics. Champaign, Illinois Natural History Survey, 1989. 43p. (Release 1.7)

WRIGHT, S. Evolution and the genetics of populations: variability within and among natural populations. Chicago, University of Chicago Press, 1978. v.4. 